\title{
The Predictive Value of Vanin-1 in Pediatric Immune Thrombocytopenia
} Mohamed Eissa', Amal Zidan², Alaa A. Omran²

${ }^{1}$ Pathology Department, College of Medicine, King Khalid University, Abha, KSA and Clinical Pathology Department, Faculty of Medicine, Zagazig University, Zagazig, Egypt

${ }^{2}$ Clinical Pathology Department, Faculty of Medicine, Zagazig University, Zagazig, Egypt

*Corresponding author: Mohamed Eissa, Mobile: 00966599151626, E-Mail: eissa20002000@yahoo.com

\section{ABSTRACT}

Background: Immune thrombocytopenia (ITP) has oxidative stress-related pathway as one of its possible mechanisms. Vanin-1 (VNN1) is an oxidative stress sensitive sensor.

Objective: The present study was conducted to assess the clinical significance of VNN1 in pediatric ITP patients.

Patients and Methods: A total of 50 kids with ITP have been involved in this work; 25 newly diagnosed, 25 chronic patients with ITP more than 12 months (15 responders and 10 non responders to treatment) and 25 apparently healthy children. All groups had their serum VNN-1 levels checked using a two-antibody sandwich enzyme-linked immunosorbent test. Results: The serum VNN1 level was significantly higher in ITP group than control group $(\mathrm{p}<0.001)$. The level of serum VNN1 was significantly very high in newly diagnosed ITP group $(\mathrm{p}<0.001)$ in comparison to chronic responders and chronic non responders ITP groups. Moreover, there was a significant increase in serum VNN1 level in chronic non responders ITP group $(\mathrm{p}<0.001)$ compared to chronic responders group. In newly diagnosed ITP group, both age $(\mathrm{r}=-0.62, \mathrm{p}=0.006)$ and the platelet count $(\mathrm{r}=-0.46, \mathrm{p}=0.01)$ had a significant negative connection with serum VNN1 level. A cut-off value lower than $0.6 \mathrm{ng} / \mathrm{ml}$ for serum VNN1 could be used to distinguish the chronic non-responders ITP from chronic responders patients with 100 percent specificity and 90 percent sensitivity.

Conclusion: From our current results, it is hypothesized that high VNN1 level plays a role in the pathogenesis and progress of pediatric ITP.

Keywords: Oxidative stress, Pathogenesis, Pediatric ITP, Responders, Vanin-1.

\section{INTRODUCTION}

When a child has thrombocytopenia, their count of platelets is lower than $100 \times 10^{9} / \mathrm{L}$, which is indicative of a hematological condition called ITP. A decrease in platelet synthesis, high platelets sequestration by spleen, or destruction due to immune reactions can all induce thrombocytopenia ${ }^{(1)}$.

In $80 \%$ of cases, ITP is a disorder that causes spontaneous bleeding from the skin and mucous membranes, primary ITP is commonly considered an autoimmune disorder. However, the majority of these cases are classified as idiopathic, while a small number occur secondary to other health issues ${ }^{(2)}$. It's been reported in numerous studies that oxidative damage may be crucial ${ }^{(3-6)}$.

There were early discoveries of the vascular noninflammatory molecules (VNN), such as the murine Vnn1 gene (mVnn1), human Vnn1 and hVnn2, as well as human Vnn3 ${ }^{(7,8)}$. Ectoenzyme VNN1 has the pantetheinase action. As a matter of fact, the liver, gut, and kidneys are all high-CoA turnover tissues where vanin1 is abundantly expressed ${ }^{\left({ }^{(9)}\right.}$.

Pantothenic acid (vitamin B5) is a critical precursor in the production of Coenzyme A (CoA), and vanin1 plays a vital role in recycling it. When it comes to fatty acid synthesizing and oxidizing processes, CoA is important since it is a heat-stable cofactor necessary for several enzyme-catalysis acetylation reactions ${ }^{(10)}$.

Pantothenic acid and cysteamine are both powerful antioxidants produced by vanin1 during CoA catabolism, when it hydrolyzes one of the substrates pantetheine's amide bonds specifically. Treatment for cystinosis may benefit from cysteamine's antioxidant properties ${ }^{(\mathbf{1 1})}$. In addition, because pantothenic acid is a structural component of CoA, its creation allows for continued manufacture of CoA. The profibrotic actions of pantothenic acid, on the other hand, appear to be due to its involvement in the encouragement of dermal fibroblast migration and proliferation (12-14).

The restoration of mitochondrial CoA levels is another benefit of pantothenic acid, resulting in increased mitochondrial function ${ }^{(15)}$. Many metabolic pathways are regulated by vanin 1 , which has been demonstrated. Mouse liver PPAR- $\alpha$ discovered to interact with the vnn1 gene, making it an excellent target for drug development. The liver's reaction to fasting is heavily regulated by PPAR- $\alpha^{(\mathbf{1 6 - 1 8})}$.

Vanin 1 is overexpressed in some disorders, which aids in the progression and aggravation of the disease. Oxidative stress role in in ITP etiology or progression has not been studied widely. A number of contradictory investigations have found that oxidative indicators involving, reduced or oxidized glutathione, and serum malondialdehyde, the total antioxidant status, and the activity of specific antioxidant enzymes fluctuate in blood levels. In peripheral leukocytes, there has been confirmed upregulation of vanin-1 (VNN1), which is a sensitive oxidative stress sensor ${ }^{(19,20)}$.

Aim of the present study was conducted to assess the clinical significance of VNN1 in pediatric ITP patients. 


\section{PATIENTS AND METHODS}

The Clinical Pathology and Pediatric Hematology and Oncology Departments of the Faculty of Medicine at Zagazig University Hospitals carried out this casecontrol study. Patients' age and gender were matched to those of a group of 25 apparently healthy volunteers who served as a control group in the study. There were 50 ITP patients in total, 25 of whom had just been diagnosed and 25 of whom had chronic ITP. Patients with long-term ITP were divided into two groups: those who responded to treatment after having ITP for more than 12 months, and those who did not respond to treatment after having ITP for more than 12 months.

K-EDETA (K-Ethylene Diamine Tetra Acetate) $(1.2 \mathrm{mg} / \mathrm{mL})$ was added to two milliliters of fresh venous blood for CBC analysis. Five $\mathrm{ml}$ blood was collected from each patient in a dry plain tube and left for 10-20 minutes at room temperature, and then the tubes were centrifuged for 20 minutes at the speed of 2000-3000 r.p.m.

Patients in the control group had standard laboratory testing as part of the study; liver and kidney function tests, Complete Blood Count (CBC) in addition to serum VNN-1 assay. The patient groups were subjected to the same investigations in addition to bone marrow aspiration examination. Human Vanin1 (VNN1) ELISA Kit (USA) was used to test the serum for the presence of VNN-1, which was detected using a double-antibody sandwich enzyme-linked immunosorbent assay.

\section{Ethical consent:}

An approval of the study was obtained from Zagazig University Academic and Ethical Committee. Every patient's parent signed an informed written consent for acceptance of sharing in the study. This work has been carried out in accordance with The Code of Ethics of the World Medical Association (Declaration of Helsinki) for studies involving humans.

\section{Statistical analysis}

In order to do the statistical analysis, we used SPSS version 17 (Statistical Package for the Social Sciences). Data were presented as mean, standard deviation, and median. Independent T-test was used to compare 2 groups with normally distributed data and MannWhitney test was used to compare 2 groups with abnormally distributed data. Kruskal-Wallis "Z" test was used to compare more than 2 groups with abnormally distributed data, and least significant difference (LSD) test was used as a post-hoc test for multiple comparison. Spearman ' $r$ ' correlation coefficients was also used. A p value of 0.05 or lower was deemed significant.

\section{RESULTS}

The study was done on 50 ITP patients and 25 healthy matched control. The demographic data for the control and patients groups are seen in table 1.

Table (1): Demographic data of control and the three ITP groups

\begin{tabular}{|c|c|c|c|c|}
\hline & $\begin{array}{l}\text { Control } \\
(n=25)\end{array}$ & $\begin{array}{l}\text { Newly diagnosed } \\
\text { ITP }(n=25)\end{array}$ & $\begin{array}{l}\text { Responder Chronic } \\
(\mathrm{n}=15)\end{array}$ & $\begin{array}{l}\text { Non responder Chronic } \\
\text { ITP }(n=10)\end{array}$ \\
\hline $\begin{array}{l}\text { Age (years) } \\
\text { Mean } \pm \text { SD } \\
\text { Median }\end{array}$ & $7.11 \pm 1.85$ & $7.83 \pm 1.03$ & $\begin{array}{c}8.7 \pm 1.91 \\
8\end{array}$ & $\begin{array}{c}7.75 \pm 1.85 \\
8\end{array}$ \\
\hline Sex & \multicolumn{4}{|c|}{ Number } \\
\hline Males & 15 & 13 & 10 & 5 \\
\hline Females & 10 & 12 & 5 & 5 \\
\hline
\end{tabular}

In this study, there was no significant difference between newly diagnosed, chronic responders and nonresponders ITP groups as regard leucocyte count, hemoglobin, hematocrit and platelets count. However, there was a significant difference regarding leucocyte count, hemoglobin, hematocrit and platelets count between ITP group and the controls (Table 2).

Table (2): Hematological parameters for control and patient groups

\begin{tabular}{|c|c|c|c|}
\hline 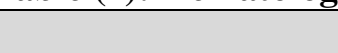 & Control $(n=25)$ & Patients $(n=50)$ & $\mathbf{P}$ \\
\hline $\begin{array}{l}\text { Leucocytes }\left(\times 10^{9} / \mathrm{L}\right) \\
\text { Mean } \pm \text { SD }\end{array}$ & $5.84 \pm 1.1$ & $8.17 \pm 1.9$ & $0.04 *$ \\
\hline $\begin{array}{l}\mathrm{RBC}\left(\mathrm{x} 10^{6} / \mathrm{mm}^{3}\right) \\
\text { Mean } \pm \text { SD }\end{array}$ & $4.29 \pm 0.56$ & $3.81 \pm 0.87$ & 1.11 \\
\hline $\begin{array}{l}\text { Hemoglobin }(\mathrm{g} / \mathrm{dl}) \\
\text { Mean } \pm \text { SD }\end{array}$ & $13.44 \pm 1.95$ & $10.88 \pm 1.39$ & $<0.001 * *$ \\
\hline $\begin{array}{l}\text { Hematocrit }(\mathrm{g} / \mathrm{dL}) \\
\text { Mean } \pm \text { SD }\end{array}$ & $40.13 \pm 4.98$ & $33.64 \pm 4.40$ & $<0.001 * *$ \\
\hline $\begin{array}{l}\text { Platelets }\left(\times 10^{3} / \mathrm{mm}^{3}\right) \\
\text { Mean } \pm \text { SD }\end{array}$ & $254.94 \pm 31.69$ & $42.73 \pm 6.08$ & $<0.001 * *$ \\
\hline
\end{tabular}

**: Highly significant - The serum VNN1 level was significantly higher in ITP group than control group (Table 4). 
Table (3): Comparison of VNN1 between control and ITP groups

\begin{tabular}{|l|c|c|c|}
\hline \multicolumn{1}{|c|}{ Variable } & Control $(\mathbf{n}=\mathbf{2 5})$ & ITP $(\mathbf{n}=\mathbf{5 0})$ & P \\
\hline VNN1 $(\mathrm{ng} / \mathrm{ml})$ & $1.13 \pm 0.20$ & $4.92 \pm 0.11$ & $<0.001^{* *}$ \\
Mean \pm SD & 0.09 & 2.95 & \\
Median & &
\end{tabular}

**: Highly significant

The level of serum VNN1 was significantly very high in newly diagnosed ITP group in comparison to chronic responders and chronic non responders ITP groups. Moreover, there was a significant increase in serum VNN1 level in chronic non responders ITP group when compared to chronic responders group (Table 4).

Table (4): Comparison of VNN1 between the three ITP groups

\begin{tabular}{|l|c|c|c|c|c|}
\hline \multicolumn{1}{|c|}{ Variable } & $\begin{array}{c}\text { Newly } \\
\text { diagnosed ITP } \\
(\mathbf{n = 2 5})\end{array}$ & $\begin{array}{c}\text { Responder } \\
\text { Chronic ITP } \\
(\mathbf{n = 1 5})\end{array}$ & $\begin{array}{c}\text { Non Responder } \\
\text { Chronic ITP } \\
(\mathbf{n = 1 0})\end{array}$ & $\mathbf{P}$ & LSD \\
\hline VNN1 (ng/ml) & $9.08 \pm 0.41$ & $0.43 \pm 0.03$ & $1.16 \pm 0.13$ & $<0.001^{* *}$ & $<0.001^{* *} 1$ \\
Mean \pm SD & 7.75 & 0.36 & 1.07 & & $<0.001^{* * 2}$ \\
Median & & & & & \\
\end{tabular}

**: Highly significant, LSD: Least significant difference. LSD: P1: Newly diagnosed versus Chronic responders, P2: Chronic responders versus Chronic non responders, P3: Newly diagnosed versus chronic non responders.

In newly diagnosed ITP group, a significant negative correlation was found between serum VNN1 level and both age and platelets count. On other hand, no significant correlations were observed between VNN1 level and the other parameters. In chronic responders and non-responders, serum VNN1 level showed no statistically significant correlation with age and all the hematological parameters (Table 5).

Table (5): Correlation between VNN1 and age and hematological parameters in the three ITP groups

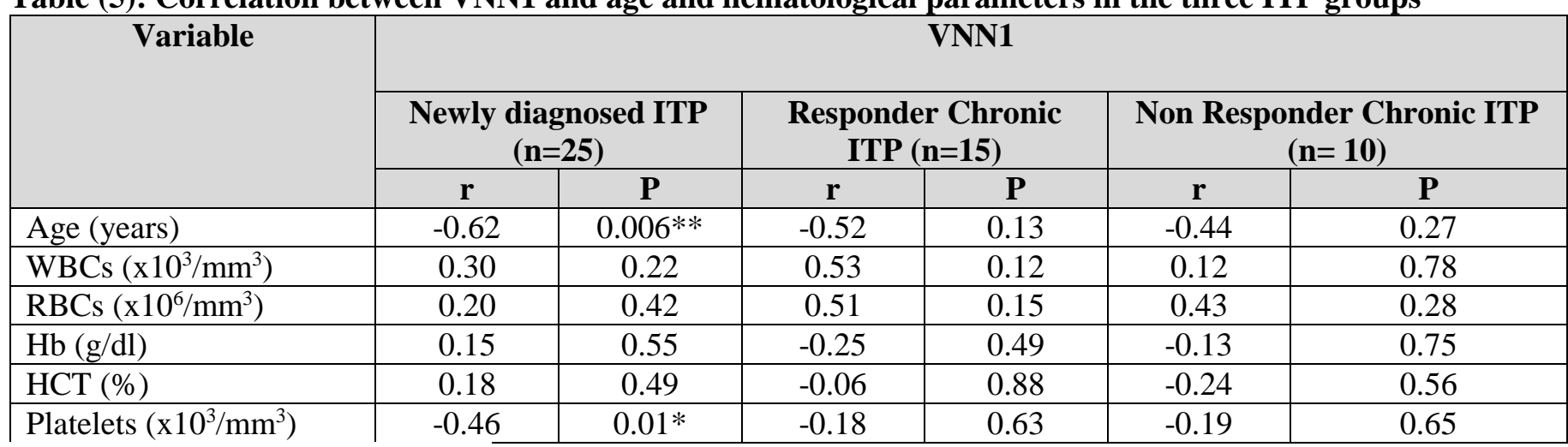

*: Significant, $* *$ : Highly significant

Table (6) showed that serum VNN1 level at a cut-off value $<0.6 \mathrm{ng} / \mathrm{ml}$ could discriminate between chronic responders and chronic non responders ITP patients with $90 \%$ sensitivity and $100 \%$ specificity.

Table (6): Validity of VNN1 in discriminating newly diagnosed ITP patients from controls

\begin{tabular}{|l|c|c|c|c|c|c|c|c|c|}
\hline & Cutoff & Sens. & Spec. & +PV & -PV & Accuracy & AUC & CI & p-value \\
\hline VNN1 & $<0.6$ & 100 & 100 & 100 & 100 & 100 & 1 & $0.9-1$ & $<0.001^{* *}$ \\
\hline
\end{tabular}

Sens.: Sensitivity, Spec.: Specificity, +PV: Positive predicted value, -PV: Negative predicted value, AUC: Area under curve, CI: Confidence interval, **: Highly significant, 


\section{DISCUSSION}

One of the most significant ITP-associated mechanisms is oxidative stress ${ }^{(3)}$. There was a substantial correlation between chronic ITP and increased expression of the oxidative stress sensor VNN1 in epithelial cells ${ }^{(\mathbf{2 1})}$. Many tissues, including the liver, kidney, and gut, express VNN1 (pantetheinase), an ectoenzyme with a GPI-anchored structure ${ }^{(9)}$. Because it catalyzes the hydrolysis of pantetheine to pantothenic acid (vitamin B5) and cysteamine, which inhibits reduced glutathione (GSH) formation. Vanin-1 causes inflammation and tissue injury by causing oxidative stress ${ }^{(22)}$.

VNN1 protein was investigated in this work in order to determine its clinical significance in immune thrombocytopenic purpura (ITP). The serum VNN1 concentration was determined using the ELISA technique, which is one of the most extensively used, most thoroughly verified, and most sensitive immunoassays currently available. Clinical laboratories and biomedical research use ELISA because it is fast, easy to use, low cost, and permits processing of even more samples than is possible with other assays. ELISA's further benefits include its great reproducibility and quantitative results.

Comparison between the serum level of VNN1 between ITP and control groups revealed a high significant increase of serum VNN1 level in ITP group than control group. Employing VNN1 to distinguish between newly diagnosed ITP and controls was found to be 90 percent sensitive and 100 percent specific when the cutoff value was set at $0.6 \mathrm{ng} / \mathrm{ml}$, with regard to the validity of using VNN1. When compared to chronic responders and chronic non-responders, the serum VNN1 level was considerably higher in the newly diagnosed ITP group than in the other two groups. Chronic non-responders ITP showed a substantial rise in serum VNN1 levels in comparison to chronic responders. Our finding goes hand in hand with Zhang et $a l .{ }^{(3)}$ and Elsalakawy et al. ${ }^{(19)}$.

Because freshly diagnosed ITP patients have higher serum VNN1 levels than other groups, this suggests that oxidative damage is present early in the course of the disease. In the meantime, patients with chronic ITP responses had the lowest amounts of VNN1 in their serum. It was discovered that the VNN1 level could distinguish between chronic responders and nonresponders with $90 \%$ sensitivity and $100 \%$ specificity, ITP patients with a cutoff level of $0.6 \mathrm{ng} / \mathrm{ml}$ are considered high-risk. To put it another way, this could be because of recovery from illness remission-induced oxidative damage. A possible etiological marker for ITP, vanin-1 may be linked to disease activity and clinical response as well as platelet count according to these data. These results support previous research that suggested oxidative stress may contribute to decrease in Treg cells in vivo ${ }^{(23)}$. MicroRNA-203 acts as a powerful septic shock repressor by reducing lung damage and inhibiting VNN1 ${ }^{(24)}$.

\section{CONCLUSION}

Based on the previous findings, we believe that oxidative stress (in the form of high VNN1 levels) may play a role in the development of chronic pediatric ITP. This hypothesis should help us to better understand the role of VNN1 in risk stratification. Agents that reduce oxidative stress, particularly in the early stages of the disease, should be studied as innovative therapy options because the administration of antioxidants during the acute phase may help patients avoid progression to chronic ITP. Down regulating VNN1 could be used to treat different disorders.

Financial support and sponsorship: Nil. Conflict of interest: Nil.

\section{REFERENCES}

1. Kistangari G, McCrae $K$ (2013): Immune thrombocytopenia. Hematol Oncol Clin North Am., 27(3):495-520.

2. Cines D, Bussel J, Liebman $\mathbf{H}$ et al. (2009): The ITP syndrome: pathogenic and clinical diversity. Blood, 113(26):6511-21.

3. Zhang B, Lo C, Shen L et al. (2011): The role of vanin1 and oxidative stress-related pathways in distinguishing acute and chronic pediatric ITP. Blood, 4569-79.

4. Kamhieh-Milz J, Bal G, Sterzer V et al. (2012): Reduced antioxidant capacities in platelets from patients with autoimmune thrombocytopenia purpura (ITP). Platelets, 23(3):184-94

5. Jin C, Dong H, Cheng P et al. (2013): Antioxidant status and oxidative stress in patients with chronic ITP. Scand J Immunol., 77(6): 482-7.

6. Akbayram S, Doğan M, Akgün C et al. (2010): The association of oxidant status and antioxidant capacity in children with acute and chronic ITP. J Pediatr Hematol Oncol., 32(4):277-81.

7. Galland F, Malergue F, Bazin $\mathrm{H}$ et al. (1998): Two human genes related to murine vanin-1 are located on the long arm of human chromosome 6. Genomics, 53(2):203-13.

8. Wang N, Qin X, Cao Y et al. (2018): Plasma vascular non-inflammatory molecule 3 is associated with gastrointestinal acute graft-versus-host disease in mice. J Inflamm., 15: 1-4.

9. Naquet $P$, Pitari G, Duprè $S$ et al. (2014): Role of the Vnn1 pantetheinase in tissue tolerance to stress. Biochem Soc Trans., 42(4):1094-100.

10. Theodoulou F, Sibon O, Jackowski $S$ et al. (2014): Coenzyme A and its derivatives: renaissance of a textbook classic. Biochem Soc Trans., 42(4):1025-32.

11. Kessler A, Biasibetti M, da Silva Melo D et al. (2008): Antioxidant effect of cysteamine in brain cortex of young rats. Neurochem Res., 33(5):737-44.

12. Kavian N, Mehlal S, Marut W et al. (2016): Imbalance of the vanin-1 pathway in systemic sclerosis. J Immunol., 197(8):3326-3335.

13. Weimann B, Hermann D (1999): Studies on wound healing: effects of calcium D-pantothenate on the migration, proliferation and protein synthesis of human dermal fibroblasts in culture. Int J Vitam Nutr Res., 69(2):113-9. 
14. Kobayashi D, Kusama M, Onda M et al. (2011): The effect of pantothenic acid deficiency on keratinocyte proliferation and the synthesis of keratinocyte growth factor and collagen in fibroblasts. J Pharmacol Sci., 115(2):230-4.

15. Giessner C, Millet V, Mostert $\mathrm{K}$ et al. (2013): Vnn1 pantetheinase limits the Warburg effect and sarcoma growth by rescuing mitochondrial activity. Life Sci Alliance, $\quad 1(4)$ : e201800073. DOI: $10.26508 / \mathrm{lsa} .201800073$

16. Rommelaere $S$, Millet $V$, Gensollen $T$ et al. (2013): PPARalpha regulates the production of serum Vanin-1 by liver. FEBS Lett., 587(22):3742-8.

17. Straus D, Glass C (2007): Anti-inflammatory actions of PPAR ligands: new insights on cellular and molecular mechanisms. Trends Immunol., 28(12):551-8.

18. van Diepen J, Jansen P, Ballak D et al. (2014): PPARalpha dependent regulation of vanin-1 mediates hepatic lipid metabolism. J Hepatol., 61(2):366-72.

19. Elsalakawy W, Ali M, Hegazy M et al. (2014): Value of vanin-1 assessment in adult patients with primary immune thrombocytopenia. Platelets, 25(2):86-92.
20. Bogdanov L, Alexandrova M, Atanasova $M$ et al. (2017): Original article. Diagnostic and prognostic potential of oxidative stress markers in adults with immune thrombocytopenia. Journal of Biomedical and Clinical Research, 9(2): 121-125.

21. Bartucci R, Salvati A, Olinga $P$ et al. (2019): Vanin 1: Its physiological function and role in diseases. Int $\mathbf{J}$ Mol Sci., 20(16):3891-95.

22. Lu P, Zhang C, Fu L et al. (2021): Near-infrared fluorescent probe for imaging and evaluating the role of vanin-1 in chemotherapy. Anal Chem., 93(29):1037810387.

23. Lundberg A, Chung R, Zeijlon L et al. (2021): Oxidative stress response in regulatory and conventional T cells: a comparison between patients with chronic coronary syndrome and healthy subjects. J Transl Med., 19(1):241-245.

24. Ling L, Lu H, Wang $H$ et al. (2019): MicroRNA-203 acts as a potent suppressor in septic shock by alleviating lung injury via inhibition of VNN1. Kidney Blood Press Res., 44(4):565-582. 